\title{
Spiral microfluidic devices for cell separation and sorting in bioprocesses
}

Cite as: Biomicrofluidics 13, 061501 (2019); https://doi.org/10.1063/1.5125264

Submitted: 21 August 2019. Accepted: 14 October 2019. Published Online: 05 November 2019

N. Herrmann, P. Neubauer, and (D) M. Birkholz
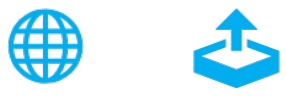

\section{ARTICLES YOU MAY BE INTERESTED IN}

Continuous separation of blood cells in spiral microfluidic devices

Biomicrofluidics 7, 054101 (2013); https://doi.org/10.1063/1.4819275

Single-cell patterning technology for biological applications

Biomicrofluidics 13, 061502 (2019); https://doi.org/10.1063/1.5123518

Cascaded spiral microfluidic device for deterministic and high purity continuous separation of circulating tumor cells

Biomicrofluidics 8, 064117 (2014); https://doi.org/10.1063/1.4903501

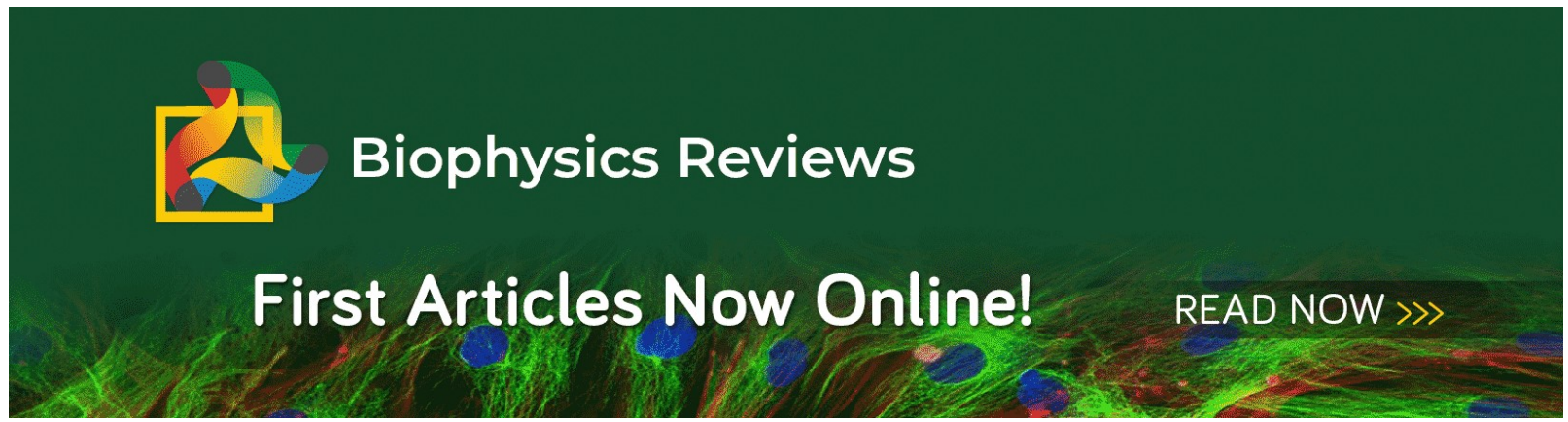




\title{
Spiral microfluidic devices for cell separation and sorting in bioprocesses
}

Cite as: Biomicrofluidics 13, 061501 (2019); doi: 10.1063/1.5125264

Submitted: 21 August 2019. Accepted: 14 October 2019.

Published Online: 5 November 2019

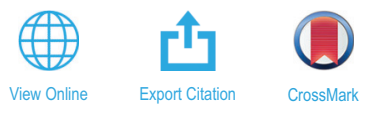

N. Herrmann, ${ }^{1, a)}$ P. Neubauer, ${ }^{7}$ and M. Birkholz ${ }^{2}$ (D)

\begin{abstract}
AFFILIATIONS
${ }^{1}$ Institute of Biotechnology, Technische Universität Berlin, Ackerstr. 76, 13355 Berlin, Germany

${ }^{2}$ HP_LEeibniz-Institut für innovative Mikroelektronik, Im Technologiepark 25, 15236 Frankfurt (Oder), Germany
\end{abstract}

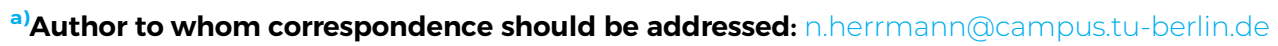

\begin{abstract}
Inertial microfluidic systems have been arousing interest in medical applications due to their simple and cost-efficient use. However, comparably small sample volumes in the microliter and milliliter ranges have so far prevented efficient applications in continuous bioprocesses. Nevertheless, recent studies suggest that these systems are well suited for cell separation in bioprocesses because of their facile adaptability to various reactor sizes and cell types. This review will discuss potential applications of inertial microfluidic cell separation systems in downstream bioprocesses and depict recent advances in inertial microfluidics for bioprocess intensification. This review thereby focusses on spiral microchannels that separate particles at a moderate Reynolds number in a laminar flow $(\operatorname{Re}<2300)$ according to their size by applying lateral hydrodynamic forces. Spiral microchannels have already been shown to be capable of replacing microfilters, extracting dead cells and debris in perfusion processes, and removing contaminant microalgae species. Recent advances in parallelization made it possible to process media on a liter-scale, which might pave the way toward industrial applications.
\end{abstract}

Published under license by AIP Publishing. https://doi.org/10.1063/1.5125264

\section{INTRODUCTION}

With more continuous bioprocesses being applied industrially, efficient cell separation methods are needed to retain productive cells in the system and thereby increasing process yield. However, currently used techniques such as microfiltration and centrifugation show various drawbacks such as membrane clogging, low scalability, and challenges in automatization. Since the introduction of first commercial cell-sorting FACS (fluorescence-activated cell sorting) systems, several chip-based microfluidic devices have been developed that offer cost-efficient solutions for the separation and sorting of cells. They can be classified into active systems like acoustophoresis, magnetophoresis, dielectrophoresis, and deterministic lateral displacement (DLD) that depend on external force fields, and passive systems that include gravitation- and inertiabased techniques. Passive systems are usually favored because of their lower complexity. Microfluidic separation techniques have been reviewed recently ${ }^{1-6}$ with some papers focusing on inertial devices in particular. ${ }^{7-11}$ Inertial separation is solely based on channel geometry and hydrodynamic forces ${ }^{12}$ without requiring cell manipulation by external forces, which makes it a robust and easy-to-use method. The most common architectures for inertial separation are straight and spiral microchannels. Straight microchannels are most commonly used for cell separation for medical purposes. Separation of circulating tumor cells, ${ }^{13,14}$ red blood cells, ${ }^{15,16}$ and MCF-7 cells ${ }^{16}$ could already be shown. Spiral channels stand out because they allow processing at higher flow rates of up to $11 / \mathrm{min}^{17}$ due to their large channel geometry. The channel structures presented here were fabricated in polydimethylsiloxane (PDMS) using soft-lithographic techniques or in poly (methyl methacrylate) (PMMA) using laser cutters. These materials can prospectively be combined with semiconductor manufacturing processes that open the door for new lab-on-chip applications with elements from both microfluidics and microelectronics. ${ }^{18}$ Medical applications of spiral microchannels today are manifold and include the isolation of circulating tumor cells, ${ }^{19,20}$ blood cells, ${ }^{21,22}$ and sperm cells, ${ }^{23}$ isolating axons from neuronal cell bodies, ${ }^{24}$ cell-cycle synchronization, ${ }^{25}$ and bloodplasma separation. ${ }^{26}$ As the channel dimensions match typical cell sizes, a variety of different cells such as mammalian cells, yeast, ${ }^{27}$ and even bacteria ${ }^{28}$ could be separated. The reproduction of large-scale processes on microfluidic devices, however, is a challenging task. $^{29}$ Currently, applying microfluidics in 
microalgae processes shows promising results. A size-dependent separation of microalgae cells with different lipid contents using dielectrophoresis and platforms for growth and oil production analysis $^{30,31}$ has already been developed. This paper reviews the potential applications of microfluidic cell separation and sorting in bioprocesses, thereby focusing on spiral channels as they show the highest potential for implementation in large-scale processes due to their energy efficiency and facile scalability.

\section{A. Separation principle in spiral microchannels}

In spiral microchannels with a laminar Poiseuille flow, i.e., Reynolds numbers $R e<2300$, three forces may cause a sizedependent separation. Shear-gradient-induced (i) and wall-induced lift forces (ii) play important roles for separation in both straight and curved microchannels. Introducing a curvature to the channel, however, induces a secondary flow that accelerates the arrangement of particles at the equilibrium position. This is caused by a secondary-flow drag force (iii), called the Dean drag.

The shear-gradient-induced lift force is caused by the parabolic velocity profile in the channel that leads to different velocities on either side of the particle. The particle thereby experiences a force pushing it to areas with lesser relative velocity differences, which can usually be found in the near-wall region. ${ }^{32}$ Thus, shear-gradient-induced lift forces counteract wall-induced lift forces and particles in that fluid stream and, therefore arrange at positions in the channel where these forces are in balance (Fig. 1). In rectangular channels, two of these equilibrium positions can be identified. They preferably form close to the center

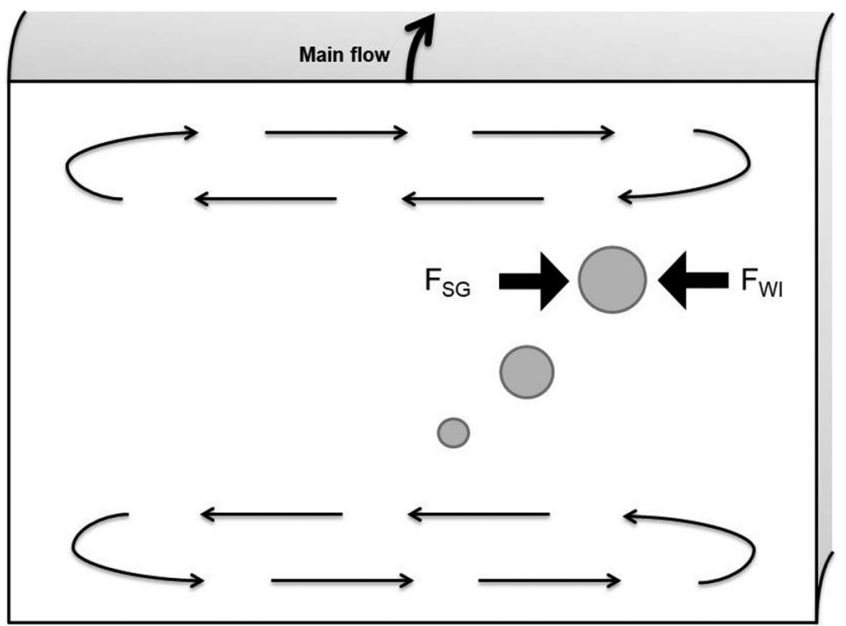

FIG. 1. Major hydrodynamic effects affecting cell positioning in curved, rectangular microchannels. Wall-induced lift forces $\left(F_{W I}\right)$ push the particles toward the channel's center, whereas shear-induced lift forces $\left(F_{S G}\right)$ direct the particles toward the side of the microchannel. By introducing a curvature to the channel, a secondary flow is induced, which applies a Dean drag $\left(F_{D}\right)$ force on the particles that support in attaining the equilibrium position. As all three hydrodynamic forces are size-dependent, differently sized cells focus at slightly different positions in the channel. of the channel's sidewalls. The magnitude of both inertial lift forces depends on the particle size, and they become stronger at higher Reynolds numbers. ${ }^{8}$ The shear-gradient lift force $F_{S G}$ can be calculated from

$$
F_{S G}=\frac{C_{S G} \rho U_{M a x}^{2} a^{3}}{D_{h}},
$$

where $C_{S G}$ is the lift coefficient for the shear gradient lift force, $\rho$ is the fluid density, $U_{M a x}$ is the fluid's maximum velocity, $a$ is the particle diameter, and $D_{h}$ is the hydraulic diameter that can be calculated for rectangular channels by $2 h \times w /(h+w)$ with $h$ and $w$ being the height and width, respectively. ${ }^{32}$ This shows that $F_{S G}$ becomes larger with decreasing channel dimensions, which shows the necessity of microstructures for efficient particle separation.

Wall-induced lift forces result from the pressure that is building up in between the particle and the wall. The particle is slowed down by the interactions with the wall, and a force is induced that directs the particles away from the channel wall toward the channel's center. $^{32}$ The wall-induced lift force $F_{W I}$ can be calculated from

$$
F_{W I}=\frac{C_{W I} \rho U_{M a x}^{2} a^{6}}{D_{h}^{4}},
$$

where $C_{W I}$ is the lift coefficient of the wall interaction force. ${ }^{32}$

Dean flows are also a result of velocity differences within the channel. As fluid parcels in the channel center move faster compared to the near-wall region, these parcels are carried toward the outer wall by the fluid's inertia, once a curvature is introduced to the channel. This leads to the recirculation of the parcels, and thereby a secondary flow is induced in the shape of two counterrotating vortices at the top and bottom surfaces of the channel (Fig. 1). ${ }^{32}$ The Dean flow is characterized by a dimensionless Dean number that is defined as

$$
D e=\operatorname{Re}\left(\frac{D_{h}}{2 R}\right)^{0.5},
$$

where $R e$ is the Reynolds number and $R$ is the average radius. Thus, smaller radii generate stronger secondary flows. ${ }^{8}$ This secondary flow imparts a drag force on particles that act differently on particles with different sizes and thereby improves the separation efficiency. ${ }^{33}$ The terminus "separation efficiency" is hereby used in a purely qualitative way for processes with two or more cell types that differ in size. It takes into account the purity of each outlet fraction and the cellular composition of the original medium as large differences in cellular abundance should also lead to higher contamination of the smaller fraction at the outlet. Another important consideration is the difference in the main cell size. As cell sizes vary a lot, an overlap in cell sizes between two different cell types will reduce the outlet fraction's purity. Increasing the flow rates strongly leads to the Dean flow becoming the dominant force, which causes dispersion of the particles rather than separation. ${ }^{12}$ The secondary-flow drag force $F_{D}$ can be calculated by

$$
F_{D}=6 \pi \mu a U_{S F}
$$


where $\mu$ is the fluid viscosity and $U_{S F}=1.8 \times 10^{-4} D e^{1.63}$ is the velocity of the secondary flow. ${ }^{32}$ Guan et al. ${ }^{34}$ examined the spiral microchannels with trapezoidal cross sections and found that stronger Dean vortices were formed on the channel side with bigger depth, which lead to an improved separation.

In addition to the three mentioned forces, several weak forces also act on the particles. These forces emerge when particles lead, lag, or rotate in the fluid stream ${ }^{8}$ and are up to several orders of magnitude weaker than the above-mentioned forces, which is why they can usually be neglected. ${ }^{32}$ Rotational lift forces become dominant only after reaching an initial equilibrium position and help the particles focusing near the channel wall's center. ${ }^{12}$ Centrifugal effects play a minor role as the particles' and fluid's densities are too similar. ${ }^{10}$

\section{APPLICATIONS OF SPIRAL MICROCHANNELS IN BIOPROCESSES}

\section{A. Replacement of microfilters}

Microfiltration plays an important role in many industrial bioprocesses $^{27}$ as particles ranging from $10 \mathrm{~nm}$ to $10 \mu \mathrm{m}$ are difficult to separate from a suspension with other common methods like centrifugation, gravitational settling, and adsorption, ${ }^{9}$ and biotechnologically relevant organisms typically range in that dimension. However, microfiltration is not flawless as membrane clogging and fouling occur frequently, which drastically reduces the efficiency of the method through, e.g., retention of proteolytic enzymes from dead cells. Substitution of membrane filters involves interrupting the process that increases the risks of contamination and accounts for a major part of operating costs. ${ }^{27}$
By increasing the flow rates in their spiral microchannels slightly from $2 \mathrm{ml} / \mathrm{min}$ to $6 \mathrm{ml} / \mathrm{min}$, Warkiani et al. ${ }^{27}$ could show that the device switches from a cell separation mode to a cell retention mode as all cells were focused at the inner wall. This allowed them to incorporate inertial microfluidics into a perfusion bioprocess. Cells were retrieved from the spiral's inner outlet and lead back into the bioreactor for further protein production, whereas the cell-free medium containing the produced protein and other small particles like cell debris was collected at the outer outlet and could be used for subsequent protein purification (Fig. 2). Replacing microfilters with spiral microfluidic devices has already been described $^{35}$ in 2007, but recent advances show that inertial microfluidics can reach throughputs at least comparable to mechanical membrane filters that can process approximately $10^{9}$ cells $/ \mathrm{ml}^{34}$ This is an essential requirement for industrial applications.

Warkiani et al. ${ }^{27}$ could show cell retention for $\mathrm{CHO}$ and yeast cells, at the example of Saccharomyces cerevisiae, in separate approaches (Table I). CHO cell retention was first conducted with a single spiral at a flow rate of $6 \mathrm{ml} / \mathrm{min}$, and a retention efficiency of $>95 \%$ could be measured for three different cell lines. They then went on to multiplex 84 microchips with four spirals each to retain the $\mathrm{CHO}$ cells at a flow rate of $500 \mathrm{ml} / \mathrm{min}$. No changes in viability, morphology, and proliferation were observed, and by measuring the expression of the shear stress biomarker c-Fos, it could be shown that no stress response could be detected in the cell, which can probably be explained by the short residence time of only $<0.1 \mathrm{~s}$ on average within the spiral. Similar to this approach, S. cerevisiae with a concentration of $10^{5}$ cells $/ \mathrm{ml}$ was retained at a lower flow rate of $2 \mathrm{ml} / \mathrm{min}$ based on smaller channel dimensions

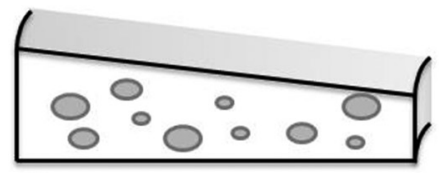

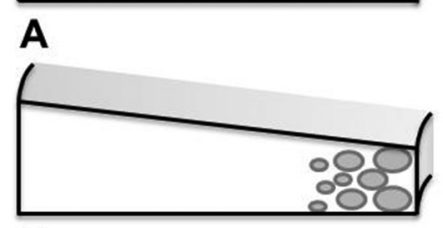

B

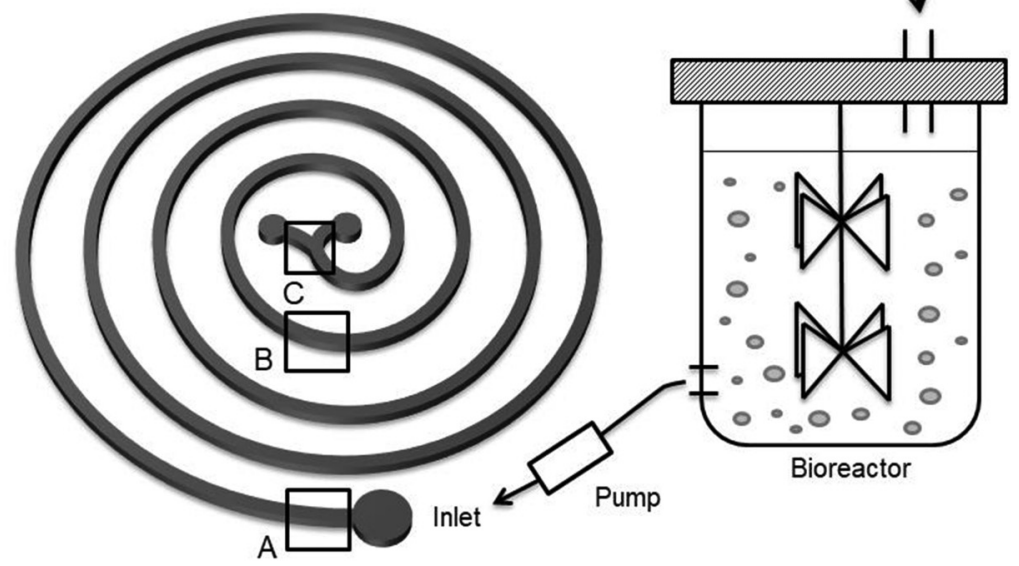

FIG. 2. General setup for cell retention with spiral and trapezoidal microchannels in perfusion bioprocesses. The medium from the bioreactor is pumped through the spiral at a specific flow rate where the dispersed cells (a) get focused at the channel's inner wall by hydrodynamic effects (b). Cells then exit the spiral from the inner outlet and are lead back into the bioreactor while the cell-free medium is obtained from the spiral's outer outlet and, e.g., used for product recovery (c). 
TABLE I. Overview of the applied process parameters for presented applications of spiral microfluidic devices.

\begin{tabular}{|c|c|c|c|c|c|c|c|c|}
\hline Application & $\begin{array}{l}\text { Cell concentration } \\
\left(\times 10^{6} \text { cells } / \mathrm{ml}\right)\end{array}$ & $\begin{array}{l}\text { Input flow } \\
\text { rate } \\
(\mathrm{ml} / \mathrm{min})\end{array}$ & $\begin{array}{c}\text { Number of } \\
\text { spirals }\end{array}$ & $\begin{array}{l}\text { Loops } \\
\text { per } \\
\text { spiral }\end{array}$ & Particle & $\begin{array}{l}\text { Dimensions } \\
(\mu \mathrm{m})\end{array}$ & $\begin{array}{l}\text { Separation/ } \\
\text { retention } \\
\text { efficiency (\%) }\end{array}$ & Reference \\
\hline Cell retention & 1.0 & $6.0^{\mathrm{a}}$ & 4 & NA & $\mathrm{CHO}$ & $80 / 130 \times 600^{b}$ & $>95$ & 27 \\
\hline Cell retention & 10.0 & 500.0 & $336^{\mathrm{c}}$ & NA & $\mathrm{CHO}$ & $80 / 130 \times 600$ & NA & 27 \\
\hline Cell retention & 0.1 & $2.0^{\mathrm{a}}$ & 8 & NA & Yeast & $30 / 70 \times 450$ & 90 & 27 \\
\hline Cell retention & $0.1(\mathrm{~g} / \mathrm{l})$ & 320.0 & $180^{c}$ & NA & Yeast & $30 / 70 \times 450$ & $>90$ & 27 \\
\hline $\begin{array}{l}\text { Cell-cycle } \\
\text { synchronization }\end{array}$ & 1.0 & 1.0 & 1 & NA & $\mathrm{CHO}$ & $80 / 130 \times 600$ & NA & 27 \\
\hline Cell retention & 4.8 & 1.0 & 1 & 8 & $\mathrm{CHO}$ & $80 / 130 \times 600$ & 99 & 36 \\
\hline Cell retention & 43.6 & 4.0 & $20^{c}$ & 6 & $\mathrm{CHO}$ & $260 / 80 \times 1000$ & $>84$ & 36 \\
\hline $\begin{array}{l}\text { Live-dead cell } \\
\text { separation }\end{array}$ & 3.5 & 1.5 & 1 & 8 & $\mathrm{CHO}$ & $80 / 130 \times 600$ & 99.7 & 41 \\
\hline $\begin{array}{l}\text { Live-dead cell } \\
\text { separation }\end{array}$ & 10.0 & 8.0 & $2^{\mathrm{d}}$ & $6 / 8$ & $\mathrm{CHO}$ & $\begin{array}{c}80 / 130 \times 600 \\
200 / 140 \times 1000\end{array}$ & 99.9 & 41 \\
\hline $\begin{array}{l}\text { Live-dead cell } \\
\text { separation }\end{array}$ & 4.0 & 6.0 & $4^{c}$ & 6 & $\mathrm{CHO}$ & $80 / 130 \times 600$ & 99.9 & 41 \\
\hline $\begin{array}{l}\text { Removal of } \\
\text { contaminants }\end{array}$ & $0.3-6.3^{e}$ & 1.0 & 1 & 8 & Microalgae & $80 / 130 \times 600$ & $>90$ & 12 \\
\hline Parallelization & NA & 1000.0 & $20^{\mathrm{c}}$ & 2.5 & Microbeads & $536 \times 3000$ & 88 & 17 \\
\hline Cascading & NA & $\begin{array}{r}22.0 \\
12.0 \\
7.0\end{array}$ & $3^{\mathrm{d}}$ & 6 & Microbeads & $\begin{array}{l}536 \times 3000 \\
336 \times 1800 \\
236 \times 1200\end{array}$ & $\sim 95$ & 17 \\
\hline
\end{tabular}

${ }^{\mathrm{a}}$ For a single spiral.

${ }^{b}$ Heights of outer walls $\times$ width of the channel base; microchannels with a trapezoidal cross section were used except for the last two applications with microbeads where rectangular channels were used.

${ }^{c}$ Parallelized spirals were used.

${ }^{\mathrm{d}}$ Cascaded spirals were used.

${ }^{\mathrm{e}} P$. tricornutum concentrations from 0.3 to $6 \times 10^{6} \mathrm{cells} / \mathrm{ml}$ and a fixed $T$. suecica concentration of $0.3 \times 10^{6}$ cells $/ \mathrm{ml}$ were used.

and cell sizes (3-5 $\mu \mathrm{m}$ for yeast compared to $10-20 \mu \mathrm{m}$ for $\mathrm{CHO}$ cells). ${ }^{27}$ Yeast cells were retained with $>90 \%$ efficiency in the single spiral and also in a multiplexed device with 180 spiral microchannels that could process $320 \mathrm{ml} / \mathrm{min}$ in the medium, which represents an improvement compared to commonly used cellulose acetate and Teflon filters. $^{27}$

In a different experiment (Table I), Warkiani and co-workers could show that even cell-cycle synchronization is possible in spiral microchannels based on size differences in the cell-cycle stages. Cells in the $G_{0} / G_{1}$ phase were separated from those in the $G 2 / M$-phase, which are generally larger in size, at a cell concentration of $10^{6}$ cells/ $\mathrm{ml}$ and a flow rate of $1 \mathrm{ml} / \mathrm{min}$. After the separation process, smaller cells with diameters $<14 \mu \mathrm{m}$ were enriched more than 2.7 -fold at the outer outlet. It would thereby be possible to retain only highly productive growing cells in the perfusion process.

In 2017, Kwon et al. ${ }^{36}$ actually incorporated spiral microfluidic devices in perfusion processes for cell retention over a course of 18-25 days with peak CHO cell concentrations of $20-30 \times 10^{6} \mathrm{cells} / \mathrm{ml}$ (Table I). In their first experiment, the process was run in a $350 \mathrm{ml}$ bioreactor for 4 days in a batch mode, with subsequent perfusion mode for another 14 days, applying a perfusion rate of two vessel volumes per day. The goal of the process was $\mathrm{IgG}_{1}$ production. On day 10 , a peak cell concentration of $22.7 \times 10^{6} \mathrm{cells} / \mathrm{ml}$ was reached with a cell viability of $99 \pm 1 \%$. For cell concentrations $<15 \times 10^{6}$ cells $/ \mathrm{ml}$, a retention efficiency of $99 \pm 2 \%$ could be achieved, which dropped to $82 \pm 3 \%$ for cell concentrations in the range of $20-23 \times 10^{6}$ cells $/ \mathrm{ml}$. Within 18 days, $263 \mathrm{mg} \operatorname{IgG}_{1}$ were produced.

Apart from the perfusion processes, Kwon and co-workers investigated cell retention efficiencies at even higher cell concentrations with increased channel dimensions $(1000 \times 260 / 80 \mu \mathrm{m}){ }^{36}$ At a flow rate of $4 \mathrm{ml} / \mathrm{min}$, retention efficiencies of $>84 \%$ could be reached for a $\mathrm{CHO}$ cell concentration of $43.6 \times 10^{6} \mathrm{cells} / \mathrm{ml}$ (Table I).

This shows that inertial microfluidic devices can also be used for processes with high cell concentrations although they probably might not be applicable for current high-density processes with cell concentrations $>100 \times 10^{6}$ cells $/ \mathrm{ml}$ because of the small channel dimensions. By parallelizing the spirals, high throughputs may be generated, which make inertial microfluidics more feasible for upscaling to industrial processes.

\section{B. Separation of live and dead cells}

Removing nonviable cells and debris is often a crucial step in bioprocesses as dead cells can affect the product yield by, for instance, releasing large amounts of proteases into the medium. ${ }^{37}$ 
They can thereby also downgrade the product's quality. In $\mathrm{CHO}$ bioprocesses, it could be shown that dead cells make up for up to $30 \%$ of the total produced biomass. ${ }^{38}$ Cell death in bioreactors amongst others is caused by apoptosis and also by shear stress through stirring and sparging in the reactor. ${ }^{37}$ Current methods for the separation of dead cells include inclined settlers ${ }^{39}$ and more recently also compact settlers. ${ }^{40}$

Kwon et al. ${ }^{41}$ applied inertial microfluidics to the separation of nonviable cells and cell debris from viable $\mathrm{CHO}$ cells. $\mathrm{CHO}$ cells are the most frequently used hosts for the expression of recombinant proteins, accounting for more than $70 \%$ of the total worldwide recombinant proteins. Separation of the generally smaller dead cells in inertial microfluidic systems is difficult, because viable and nonviable cells overlap partly in size, which sets a natural limit for the efficiency of the separation process. ${ }^{41}$ The size difference is caused by cell-shrinkage at the early stages of apoptosis, which is important for regulating the activity of apoptotic nucleases and caspases. ${ }^{42}$ In their experiments, ${ }^{41}$ Kwon and co-workers focused on maintaining high viable cell concentrations while concurrently removing as many dead cells as possible.

In the first experiment (Table I), their system was tested for the separation of cells $<10 \mu \mathrm{m}$ with $3.5 \times 10^{6}$ cells $/ \mathrm{min}$, a flow rate of $1.5 \mathrm{ml} / \mathrm{min}$, and a split ratio of 0.36 , which is defined as the outer outlet flow rate divided by the inner outlet flow rate. Dead cells and debris were focused at the outer outlet, and a live cell retention efficiency of $99.7 \%$ was achieved with a dead cell removal efficiency of $6.1 \%$. They then proceeded to characterize their device by examining the correlation of cell concentration, flow rate, cell viability, and flow split ratio on live cell retention efficiency, dead cell removal efficiency, and dead cell removal purity, which they defined as a portion of nonviable cells in the outer outlet (Table II). Particularly, cell concentration seems to have a big impact on the separation process, which can be explained by an

TABLE II. Effect of process parameters on separation measures, measured at cell concentrations from 1 to $10 \times 10^{6}$ cells $/ \mathrm{ml}$, flow rates from 0.9 to $1.5 \mathrm{ml} / \mathrm{min}$, viabilities from $30 \%$ to $80 \%$, and flow split ratios from 0.32 to 0.85 in a spiral microfluidic device with eight loops, an inner depth of $80 \mu \mathrm{m}$, an outer depth of $130 \mu \mathrm{m}$, and a width of $600 \mu \mathrm{m} .^{41}$

\begin{tabular}{lcccc}
\hline \hline & $\begin{array}{c}\text { Cell } \\
\text { concentration }\end{array}$ & $\begin{array}{c}\text { Input } \\
\text { flow rate }\end{array}$ & $\begin{array}{c}\text { Cell } \\
\text { viability }\end{array}$ & $\begin{array}{c}\text { Flow split } \\
\text { ratio }\end{array}$ \\
\hline $\begin{array}{l}\text { Live cell retention } \\
\text { efficiency }\end{array}$ & - & 0 & 0 & - \\
$\begin{array}{l}\text { Dead cell removal } \\
\text { efficiency }\end{array}$ & ++ & + & - & ++ \\
$\begin{array}{l}\text { Dead cell removal } \\
\text { purity }\end{array}$ & -- & + & - & $-{ }^{\mathrm{d}}$ \\
\hline \hline
\end{tabular}

${ }^{a}$ Fraction of total viable cells in the inner outlet.

${ }^{b}$ Fraction of total dead cells in the outer outlet.

${ }^{\mathrm{c}}$ Purity of nonviable cells in the outer outlet.

${ }^{\mathrm{d}} 0$ means no correlation was observed; - means weak negative correlation; -- means strong negative correlation (separation measures change $>10 \%$ in measured range); + means weak positive correlation; ++ means strong positive correlation (separation measures change $>10 \%$ in the measured range). increase of cell-to-cell interactions in the small microchannel with increasing cell concentration. In their final experiment, the effects of cascading and parallelization on the separation efficiency were investigated. For cascading, a wide spiral with six coils was connected to the already characterized narrow microchannel with 8 coils as a first stage of size-dependent separation (Table I). The flow rate could be increased to $8 \mathrm{ml} / \mathrm{min}$ and the cell concentration was set to $10 \times 10^{6}$ cells $/ \mathrm{ml}$. This resulted in a live cell retention efficiency of $99.9 \%$, while the dead cell removal efficiency dropped to $3.4 \%$. In a parallel approach with four spirals (Table I) and an inverted fluid flow at $4 \times 10^{6}$ cells $/ \mathrm{ml}$ cell concentration and $6 \mathrm{ml} / \mathrm{min}$ flow through, the same live cell retention efficiency could be reached but the dead cell removal efficiency dropped even further to $3 \%$. However, even a small dead cell removal efficiency can have a big impact on bioprocesses as microfluidic systems can be run continuously.

\section{Removal of contaminants in microalgae cell cultures}

Microalgae cells are becoming more prominent in biotechnological processes, particularly, as a source of biomass and production hosts for biofuels because of their ability to capture carbon dioxide. ${ }^{12}$ However, processes working with microalgae cells are especially susceptible to contaminations, primarily by zooplankton, phytoplankton-lytic bacteria, virus, and other algae due to difficult sterilization processes. ${ }^{43}$ These cross-contaminations with other microalgae species are often inevitable. Resource competition and secretion of harmful secondary metabolites thereby lead to drastic decreases in process yield and product quality. Current methods to treat these contaminations include microfiltration, addition of chemicals acting against the pollutant, and changes in environmental conditions such as harsh changes in $\mathrm{pH}^{43}$

In laboratory setups, time-consuming and labor-intensive techniques such as serial dilutions and selective agar plates are usually applied to reduce contaminations. Syed et al. ${ }^{12}$ investigated the potential of inertia-based microfluidic systems on separating the common invading microalgae Phaeodactylum tricornutum from a culture of Tetrasemis suecica cells. After tests with $6 \mu \mathrm{m}$ and $10 \mu \mathrm{m}$ microbeads and microalgae cells, they found that the best separation was reached at a flow rate of $1 \mathrm{ml} / \mathrm{min}$. The fusiform $P$. tricornutum with approximate diameters of $25.7 \pm 3.5 \mu \mathrm{m}$ was focused at the outer outlet whereas T. suecica with a diameter of $10.7 \pm 0.8 \mu \mathrm{m}$ exited through the inner outlet. Both cell types were focused with efficiencies of $>90 \%$. In the second experiment (Table I), cell concentrations of $P$. tricornutum were gradually increased from $0.3 \times 10^{6} \mathrm{cells} / \mathrm{ml}$ to $6 \times 10^{6} \mathrm{cells} / \mathrm{ml}$, while the T. suecica concentration was maintained at $0.3 \times 10^{6}$ cells $/ \mathrm{ml}$ to investigate the impact of pollutant concentration on the separation process. At all concentrations, $P$. tricornutum focusing efficiencies remained over $90 \%$, which demonstrates the insensitivity of the method to the contaminant's concentration. After the separation, no measurable change in T. suecica vitality could be detected, which distinguishes inertial microfluidic cell separation from other common methods for the removal of contaminants. T. suecica was then reinoculated to test the sustainability of the purification process and it was found that $P$. tricornutum contamination 
remained suppressed until day 10, and at the end of the third week, the contamination was still 50 times lower than that in unpurified samples. By applying the separation process, for instance, at a two-week interval, $P$. tricornutum contamination could be suppressed. However, it was remarked that parallelization of the process is essential for upscaling to an industrial scale.

$\mathrm{Li}$ and co-workers ${ }^{44}$ also worked on separating microalgae cells. They used straight microchannels to separate cells of the biodiesel producing alga Euglena gracilis based on different shapes of the same organism to gain a shape-synchronized population. $10^{5}$ cells/min could thereby be separated using five different outlets. In a different experiment by Condina et al., ${ }^{45}$ spiral microchannels were used to separate beer spoilage bacteria from yeast for subsequent identification using mass spectrometry. Separation efficiencies of $>90 \%$ were reached at a flow rate of $1.5 \mathrm{ml} / \mathrm{min}$. They could thereby improve the limit of detection for common contaminating bacteria in the beer industry and reduce the time for the detection of contaminations.

\section{Bead-linked separation of specific cells and proteins}

For spiral microchannels, a confinement ratio of $a / D_{h}>0.07$ was shown empirically, below which all the particles flow through the outer outlet. ${ }^{46}$ This follows the fact that the minimal cell size that can be focused in spiral microfluidic devices is limited by the channel dimensions. Sarkar et al. ${ }^{47}$ developed a method that can evade this problem by linking cells to microbeads of different sizes with subsequent microfluidic separation. By binding specific cells to antibody-coated microbeads $(10$ and $15 \mu \mathrm{m})$ with biotinstreptavidin linkages in a single binding step, they were even able to separate CD4+ from CD8+ T cells and T cells from B cells, although these cells show only minimal differences in size $(6-8 \mu \mathrm{m})$. For the latter approach, microbeads were coated with anti-CD3 and anti-CD19 antibodies, respectively. Their Dean Flow Fractionation Device (channel height was $115 \mu \mathrm{m}$ ) was thereby able to process around $10^{5}$ beads/s. It could be observed that the focusing position in the channel was determined by the bigger part of the bead-cell pair. In case microbeads and cells had the same size, an additive effect of the two sizes on the focusing behavior was observed. In a different approach, Sarkar and co-workers separated three specific HIV-antibodies from the total IgG-fractions of serum containing less than $1 \%$ antibodies that they targeted. ${ }^{47}$ Smaller microbeads with diameters of $10,4.5$, and $1 \mu \mathrm{m}$ were used to improve the surface to mass ratio, which, in turn, improves the antibody binding efficiency. Approximately $95 \%$ of all three antigen-specific antibodies were purified with less than $5 \%$ cross-contaminations.

The bead-linked separation approach could be used in the purification process of monoclonal antibodies and for separating small cells like bacteria, which has only been done in few cases. ${ }^{28,48}$ A cascaded setup could potentially even enable the separation of a large number of different proteins or similar-sized cells.

\section{ADVANCES IN THROUGHPUT}

For most industrial processes, cell separation with flow rates in the milliliter-scale, as shown by the previously mentioned applications, is insufficient. A single microchannel, however, can only process small flow rates while still maintaining efficient particle separation. Increasing the flow rates in microfluidic devices can, therefore, only be done effectively by cascading or parallelization. Efficient upscaling of channel dimensions is restricted by the confinement ratio and as the biotechnologically relevant group of bacteria is very small (about $1 \times 3 \mu \mathrm{m}$ for $E$. coli $^{49}$ ), channel dimensions have to be maintained small, too. Cascading has already been applied, e.g., for the separation of cells from blood samples ${ }^{50,51}$ but the focus rather lies on reaching higher separation efficiency compared to single devices than increasing the throughput. Parallelization is difficult because in-plane parallelization would occupy too much space and stacked systems suffer from differences in inlet pressure depending on the distance of the microchip to the pump.

Since the flow rate is a constitutive factor for reaching wanted equilibrium positions, Miller et al. ${ }^{17}$ developed a modular manifold, enabling equal inlet pressure distribution on a stack of 20 spiral microchannels with a toroidal channel design (Table I). This allowed them to separate the microbeads with sizes of 45 and $250 \mu \mathrm{m}$ at a flow rate of $11 / \mathrm{min}$, which excels previous parallelization approaches of inertia-based devices significantly. ${ }^{27,48}$ They thereby focused on $\sim 88 \%$ of the large microbeads at the inner outlet while $\sim 73 \%$ of the small particles exited the spiral through the outer outlet.

In a cascaded approach (Table I), described in the same paper, Miller and co-workers used spirals of three different widths $(500,300$, and $200 \mu \mathrm{m})$ to separate microbeads reaching from 1 to $300 \mu \mathrm{m}$. Cascading allowed them to successively remove larger particles down to the smallest microbeads. To increase the recovery rates, two recirculations were performed per separation step. By using a spiral with a comparably large cross-sectional area first, higher flow rates can be applied. It was also shown empirically in their experiments that for large spirals $(>300 \mu \mathrm{m})$, the minimum focusing size rather correlates with $0.021356 \times \mathrm{H}^{1.33623}$ where $\mathrm{H}$ is the channel height. In this case, an initial flow rate of $22 \mathrm{ml} / \mathrm{min}$ was set, which automatically decreased to $12 \mathrm{ml} / \mathrm{min}$ in the second spiral and $7 \mathrm{ml} / \mathrm{min}$ in the third spiral. In the $500 \mu \mathrm{m}$ spiral, $\sim 95 \%$ of particles $>95 \mu \mathrm{m}$ could be focused, whereas in the $200 \mu \mathrm{m}$ spiral, $\sim 96 \%$ of particles $>50 \mu \mathrm{m}$ were separated. Increasing the number of recirculations could eventually increase the separation efficiencies even further.

However, it should be taken into account that most industrial bioprocesses are based on cell cultures with densities several orders of magnitude higher compared to the cell suspensions in the described experiments. Cell concentrations can easily exceed $10^{7}-10^{8}$ cells $/ \mathrm{ml} .^{52}$ This leads to a severe increase in cell-to-cell interactions and might subsequently lead to clogging of the microchannel. In a recent work by Moloudi et al., particle separation in scaled-up microchannels (500/ $900 \times 2000 \mu \mathrm{m})$ was examined. By increasing the channel size at a constant throughput, cell-to-cell interactions could be reduced. It was shown that increased channel dimensions clearly lower the inertia of flow but particle separation was still possible. In addition, it could be shown that even a single-loop trapezoidal channel is able to separate the particles sufficiently. Reducing 
the channel's length could, therefore, be another possibility to decrease the risk of clogging without diminishing the device's performance too heavily. The experiments ${ }^{53}$ were conducted using a suspension of microcarriers ( $100 \mu \mathrm{m}$ diameter $)$ and mesenchymal stem cells. As shown by Moloudi et al. in 2018, ${ }^{54}$ microcarriers can be separated from mesenchymal stem cells at a flow rate of $30 \mathrm{ml} / \mathrm{min}$ and with a total yield of $94 \%$ using spiral microchannels. This indicates that an increased throughput can not only benefit cell separation for industrial purposes but also for medical applications. Different medically relevant cell types like the aforesaid mesenchymal stem cells, circulating tumor cells, ${ }^{19,20}$ and chondrocytes ${ }^{55}$ could thereby be separated even faster from cell mixtures.

\section{CONCLUSIONS}

Inertial microfluidic systems could already be applied in several bioprocessing steps, including replacement of microfilters, live-dead cell separation, removal of contaminating microalgae species, and separation of specific cells and proteins by linkage to differently sized beads. As applying inertial systems for bioprocesses was just introduced recently, it is expected that the presented methods will be severely improved in the following years. The flexibility and scalability of these systems also allow for application to entirely different processes. The most relevant issue currently is parallelization, which is essential for upscaling to the industrial scale. As natural limits are set for the flow rate in a microchannel, cascading and parallelization are the only ways to increase the throughput beyond $11 / \mathrm{min}$ while still maintaining efficient particle separation. Although parallelizing the microchannels appears easy, pumps are needed, leading to high energy costs with increasing system size, which might make these systems unfeasible for industrial scale processes. Risks of system failure are, however, minimized by a parallel setup. These risks include primarily the clogging of the microchannels through cell agglomeration. Inertial microfluidic systems still have to be adapted to some biotechnologically relevant organisms like fungi and bacteria. The bead-linked approach could help here to apply microfluidic separation processes to other protists of different sizes.

\section{ACKNOWLEDGMENTS}

We gratefully acknowledge the funding from the Federal German Ministry of Education and Science (BMBF) for the program "New products for the bioeconomy," Project No. 031B0381 (SepaDiElo).

\section{REFERENCES}

${ }^{1}$ D. R. Gossett, W. M. Weaver, A. J. MacH, S. C. Hur, H. T. K. Tse, W. Lee, H. Amini, and D. Di Carlo, Anal. Bioanal. Chem. 397, 3249 (2010).

${ }^{2}$ A. Dalili, E. Samiei, and M. Hoorfar, Analyst 144, 87 (2018).

${ }^{3}$ D. Stoecklein and D. Di Carlo, Anal. Chem. 91, 296 (2019).

${ }^{4}$ N. Pamme, Lab Chip 7, 1644 (2007).

${ }^{5}$ C. W. Shields IV, C. D. Reyes, and G. P. López, Lab Chip 15, 1230 (2015).

${ }^{6}$ A. A. S. Bhagat, H. Bow, H. W. Hou, S. J. Tan, J. Han, and C. T. Lim, Med.

Biol. Eng. Comput. 48, 999 (2010).

${ }^{7}$ D. Di Carlo, Lab Chip 9, 3038 (2009).
${ }^{8}$ H. Amini, W. Lee, and D. Di Carlo, Lab Chip 14, 2739 (2014).

${ }^{9}$ J. P. Dijkshoorn, M. A. I. Schutyser, R. M. Wagterveld, C. G. P. H. Schroën, and R. M. Boom, Sep. Purif. Technol. 173, 86 (2017).

${ }^{10}$ J. Zhang and D. Yuan, Lab Chip 16, 10 (2015).

${ }^{11}$ Y. Gou, Y. Jia, P. Wang, and C. Sun, Sensors 18, 1762 (2018).

${ }^{12}$ M. S. Syed, M. Rafeie, D. Vandamme, M. Asadnia, R. Henderson, R. A. Taylor, and M. E. Warkiani, Bioresour. Technol. 252, 91 (2018).

${ }^{13}$ H. Lim, S. M. Back, M. H. Hwang, D. Lee, H. Choi, and J. Nam, Micromachines 10, 462 (2019).

${ }^{14}$ A. Kulasinghe, J. Zhou, L. Kenny, I. Papautsky, and C. Punyadeera, Cancers 11, 1 (2019).

${ }^{15}$ G. A. Barabino, J. Biomech. Eng. 140, 061013 (2018).

${ }^{16}$ C. Liu, C. Xue, X. Chen, L. Shan, Y. Tian, and G. Hu, Anal. Bioanal. Chem. 87, 6041 (2015).

${ }^{17}$ B. Miller, M. Jimenez, and H. Bridle, Sci. Rep. 6, 36386 (2016).

${ }^{18}$ M. Birkholz, A. Mai, C. Wenger, C. Meliani, and R. Scholz, WIREs Nanomed. Nanobiotechnol. 8, 355 (2016).

${ }^{19}$ M. E. Warkiani, B. L. Khoo, L. Wu, A. K. P. Tay, A. A. S. Bhagat, J. Han, and C. T. Lim, Nat. Protoc. 11, 134 (2015).

${ }^{20}$ A. You, M. A. Y. Be, and I. In, Biomicrofluidics 8, 064117 (2014).

${ }^{21}$ A. You, M. A. Y. Be, and I. In, Biomicrofluidics 7, 054101 (2013).

${ }^{22}$ L. Wu, G. Guan, H. W. Hou, A. A. S. Bhagat, and J. Han, Anal. Chem. 84, 9324 (2012).

${ }^{23}$ J. Son, R. Samuel, B. K. Gale, D. T. Carrell, J. M. Hotaling, and J. M. Hotaling, Biomicrofluidics 11, 054106 (2017).

${ }^{\mathbf{2 4}}$ S. Kim, J. Park, A. Han, and J. Li, Neural Regen. Res. 9, 1703 (2014).

${ }^{25}$ W. C. Lee, A. A. S. Bhagat, S. Huang, K. J. Van Vliet, J. Han, and C. T. Lim, Lab Chip 11, 1359 (2011).

${ }^{26}$ M. Rafeie, J. Zhang, M. Asadnia, W. Li, and M. E. Warkiani, Lab Chip 16, 2791 (2016).

${ }^{27}$ M. E. Warkiani, A. K. P. Tay, G. Guan, and J. Han, Sci. Rep. 5, 11018 (2015).

${ }^{28}$ T. Roth, L. Sprenger, S. Odenbach, and U. O. Häfeli, Phys. Fluids 30, 045102 (2018).

${ }^{29}$ P. Ho, C. Westerwalbesloh, E. Kaganovitch, A. Grünberger, P. Neubauer, D. Kohleyer, and E. von Lieres, Microorganisms 7, 105 (2019).

${ }^{30}$ H. S. Kim, A. R. Guzman, H. R. Thapa, T. P. Devarenne, and A. Han, Biotechnol Bioeng. 113, 1691 (2016).

${ }^{31}$ H. S. Kim, T. L. Weiss, H. R. Thapa, T. P. Devarenne, and A. Han, Lab Chip 14, 1415 (2014).

${ }^{32}$ J. M. Martel and M. Toner, Annu. Rev. Biomed. Eng. 16, 371 (2014).

${ }^{33}$ J. M. Martel and M. Toner, Phys. Fluids 24, 032001 (2012).

${ }^{34}$ G. Guan, L. Wu, A. A. Bhagat, Z. Li, P. C. Y. Chen, S. Chao, C. J. Ong, and J. Han, Sci. Rep. 3, 1475 (2013).

${ }^{35}$ J. Seo, M. H. Lean, and A. Kole, Appl. Phys. Lett. 91, 033901 (2007).

${ }^{36}$ T. Kwon, H. Prentice, J. De Oliveira, N. Madziva, M. E. Warkiani, J. F. P. Hamel, and J. Han, Sci. Rep. 7, 6703 (2017).

${ }^{37}$ D. Brindley, K. Moorthy, J. H. Lee, C. Mason, H. W. Kim, and I. Wall, J. Tissue Eng. 2011, 620247 (2011).

${ }^{38}$ T. Klein, N. Heinzel, P. Kroll, M. Brunner, C. Herwig, and L. Neutsch, J. Biotechnol. 207, 67 (2015).

${ }^{39}$ B. C. Batt, R. H. Davis, and D. S. Kompala, Biotechnol. Prog. 6, 458 (1990).

${ }^{40}$ C. A. Freeman, P. S. D. Samuel, and D. S. Kompala, Biotechnol. Prog. 33, 913 (2017).

${ }^{41}$ T. Kwon, R. Yao, J. F. P. Hamel, and J. Han, Lab Chip 18, 2826 (2018).

${ }^{42}$ C. D. Bortner and J. A. Cidlowski, Cell Death Differ. 9, 1307 (2002).

${ }^{43}$ H. Wang, W. Zhang, L. Chen, J. Wang, and T. Liu, Bioresour. Technol. 128, 745 (2013).

${ }^{44}$ M. Li, H. E. Muñoz, K. Goda, and D. Di Carlo, Sci. Rep. 7, 1 (2017).

${ }^{45}$ M. R. Condina, B. A. Dilmetz, R. Bazaz, J. Meneses, M. Ebrahimi, and P. Hoffmann, Lab Chip 19, 1961 (2019).

${ }^{46}$ D. Di Carlo, D. Irimia, R. G. Tompkins, and M. Toner, Proc. Natl. Acad. Sci. U. S. A. 104, 18892 (2007). 
${ }^{47}$ A. Sarkar, H. W. Hou, A. E. Mahan, J. Han, and G. Alter, Sci. Rep. 6, 23589 (2016).

${ }^{48}$ A. J. Mach and D. di Carlo, Biotechnol. Bioeng. 107, 302 (2010).

${ }^{49}$ G. Reshes, S. Vanounou, I. Fishov, and M. Feingold, Biophys. J. 94, 251 (2008).

${ }^{50} \mathrm{M}$. Robinson, H. Marks, T. Hinsdale, K. Maitland, and G. Coté, Biomicrofluidics 11, 024109 (2017).

${ }^{51}$ A. Abdulla, W. Liu, A. Gholamipour-Shirazi, J. Sun, and X. Ding, Anal. Chem. 90, 4397 (2018).
${ }^{52}$ F. Tapia, D. Vázquez-Ramírez, Y. Genzel, and U. Reichl, Appl. Microbiol. Biotechnol. 100, 2121 (2016).

${ }^{53}$ R. Moloudi, S. Oh, C. Yang, K. L. Teo, A. Tin, L. Lam, M. Ebrahimi, and M. W. Naing, Biotechnol. J. 14, 1800674 (2019).

${ }^{54}$ R. Moloudi, S. Oh, C. Yang, K. L. Teo, A. T. Lam, M. E. Warkiani, and M. W. Naing, Sci. Rep. 8, 1 (2018).

${ }^{55}$ C. A. Tee, Z. Yang, L. Yin, Y. Wu, J. Han, and E. H. Lee, Biomaterials 220, 119409 (2019). 